\title{
A Comparative Evaluation of Micro Leakage of Two Different Bulk Fill Composites with Ever X Posterior Composite For Class II Restorations By Dye Extraction Method- An in Vitro Study
}

\author{
Setu R. Bavaria ${ }^{1}$, Nimisha C. Shah ${ }^{2,}$ Ruchirani P. Shah ${ }^{3}$, Deep J. Makati ${ }^{4}$ \\ ${ }_{1,23,4}$ (Department of conservative dentistry and endodontics, $K$. M. Shah Dental College and Hospital / \\ Sumandeep Vidyapeeth, India)
}

\begin{abstract}
To evaluate \& compare microleakage in class II cavities restored with three different bulk fill composites. Forty five sound first molars free of caries, cracks, decay and restorations were selected for this study._Class II cavity slot preparations were made with the following dimensions, buccolingual-4 mm, mesiodistally- $4 \mathrm{~mm}$, and $4 \mathrm{~mm}$ depth were prepared. The gingival margin was placed $1 \mathrm{~mm}$ below CEJ. The test specimens were randomly divided into three groups GROUP 1: Silorane composite, Group 2:- Tetric evoceram bulk fill, Group 3: Ever X posterior. Teeth were polished \& thermo cycled for 400 cycles between 5 degree $C$ and 55 degree $C$.The radicular apices of teeth were sealed \& covered with nail varnish except for 1-2 $\mathrm{mm}$ around the margins of restorations. After placing in 2\% methyline blue dye for 24 hours the samples were washed and processed for dye extraction. The teeth were placed in test-tube containing $1 \mathrm{ml}$ of concentrated (65 wt \%) nitric acid for 3 days. Test-tube was centrifuged at 5,000 rpm for 5 minutes. Two hundred microliters of the supernatant from each sample was transferred to a 96-well plate. Sample absorbance was read by an automatic spectrophotometer. Statistical analyses used were one way analysis of variance, post hoc analysis. Results showed that ever $X$ posterior showed least microleakage followed by Tetric evoceram bulkfill and Silorane composite. There was a statistically significant difference between group 3 and group $1 \& 2$, however there was no significant difference between group $1 \& 2$. The present study concluded that Fiber reinforced ever $X$ Posterior showed least microleakage compared to Tetric evoceram bulk fill and Silorane composite
\end{abstract}

Keywords : ever $X$ posterior, microleakage, bulk fill, dye extraction

\section{Introduction}

By tradition for class I and class II restorations, silver amalgam was the material of choice. Declining acceptance of amalgam alloys plus patients constantly increasing interest in aesthetics resulted in the development of new tooth colored restoratives and techniques. ${ }^{1}$ as composites were introduced in 1960s and have been available for nearly 50 years and since then have undergone a lot of research and development. Conventional posterior composites have failed to be an ideal amalgam alternative due to several well known reasons mainly to establish an adequate proximal contact causing microleakage. Micro leakage provokes sensitivity, can lead to colonization of microorganisms leading to secondary caries and subsequent pulpal infection and a clinically failed restoration. The development of low shrinkage matrix resins like Silorane has to some extent minimized trouble related to polymerization shrinkage. In these resins, polymerization takes place by cationic "ring - opening" mechanism causing negligible polymerization shrinkage of less than $1 \%$ thus, causes minimal microleakage A new restorative material - TETRIC N CERAM is evolved recently which is a light cured, nano-hybrid direct composite for posterior teeth restoration .It can be applied in bulk increments of up to $4 \mathrm{~mm}$, can be sculpted and polymerised in just $10 \mathrm{sec}$ without compromising the material's physical properties.

More recently another breakthrough in field of restorative dentistry is - Fiber-Reinforced Composite. The use of fibre-reinforced composites has become increasingly important in diverse high-technology industries over the recent years. A composite material was developed with ever $\mathrm{x}$ Posterior equipped with short glass fibres and usable as a substitute for dentine; its fibres mimic the collagen fibres of dentine and therefore achieve a higher fracture toughness for restoration $\left(5.1 \mathrm{MPA} / \mathrm{m}^{1 / 2}\right)$. Thus, Ever X posterior, due to its specific material structure, provides new options in restorations of large cavities in the posterior area thanks to its exceptional fracture toughness which prevent the occurrence of fractures in the filling.

However, a limited literature is available to assess microleakage for Silorane, bulk fill Tetric Evoceram and fiber reinforced Ever X posterior in class II (MO / DO) cavities using dye extraction method. Thus, purpose of this study was to evaluate and compare amount of microleakage using dye extraction method when single increment bulk fill composites were used 
The null hypothesis stated was that there will be, "NO STATISTICALLY SIGNIFICANT difference in microleakage around gingival margin when three different bulk fill composites will be used in single increment for class II (MO/DO) cavities in molars."

\section{Material And Method}

Total of forty five mandibular / maxillary first molars free of caries, cracks, decay and restorations were selected for this study. Calculus was removed from external root surfaces with an ultrasonic scaler. All the selected teeth were stored in $0.5 \%$ chloramine $\mathrm{T}$ solution for 12 hours, and then washed and transferred to $0.9 \%$ saline solution. Each specimen was mounted with the neighboring tooth to place tofflemire matrix which allows build up of proximal wall. Disto oclussal / Mesio occlusal class II cavity slot preparations was made with the following dimensions,

$>$ Bucco-lingually- $3 \mathrm{~mm}$,

$>$ Mesio-distally- $3 \mathrm{~mm}$,

$>$ Depth $-5 \mathrm{~mm}$

The gingival margin was placed $1 \mathrm{~mm}$ below CEJ. Each Cavity was prepared with a carbide bur (\#836R, Diatech). For every five cavity preparations, a new bur was used.The test specimens were divided into three groups by simple random sampling method.

$>$ Group 1 :- silorane composite (filtektm p90, 3m, ESPE)

$>$ Group 2 :- tetric $n$ ceram bulk fill ( Ivoclar)

$>$ Group 3 :- Ever X posterior ( GC India)

All the cavities were cleaned using water spray and gently dried followed by placement of tofflemire matrix and light transmitting wedge which allowed building up of the proximal wall.

In Group 1: Silorane Composite (Filtektm P90, 3m, Espe)

$>$ Silorane system self etch primer was applied to the enamel and dentin surfaces with an applicator tip and agitated for $15 \mathrm{sec}$.

$>$ The excess solvent was evaporated with a gentle blast of air for 10 seconds and the primer was light cured for 10 seconds.

$>$ This was followed by the application of silorane bond (Filtek P90) with an applicator tip.

$>$ After dispersing the silorane bond to a homogenous film by oil free air blow for 10 seconds the bond was light cured for 10 seconds.

$>$ Cavity was filled using a single increment of the silorane material (Filtek P90), cured for 20 secs using the continuous curing cycle.

In Group 2:- Tetric N Ceram Bulk Fill (Ivoclar)

$>$ The self etching primer \& self etch bond,(ivoclar) for tetric $\mathrm{N}$ ceram were gently applied to the cavity surface, air dried, and then light cured for $20 \mathrm{sec}$.

$>$ The class II cavities were packed using single increment dispensed from specially designed gun provided by the manufacturer

$>$ Cured for 20 seconds with a LED curing light ramp mode for 20 seconds.

In Group 3: Ever X Posterior (Gc India)

$>$ To build the substructure, enamel was etched and bonded.

$>$ A thin layer of flowable composite was placed on the floor of the cavity and cured.

$>$ The cavity wall was built using nano hybrid composite.

$>$ The cavities were filled with a single increment of $4 \mathrm{~mm}$ of EVER X POSTERIOR dispensed from specially designed gun provided by the manufacturer and cured for 20 seconds.

$>$ Last occlusal layer of cavity was filled by Nanohybrid composite.

After the teeth were restored, they were polished with polishing bur and soflex discs. Discs were replaced for every ten samples. The samples were then stored in distilled water for 24 hours at $37{ }^{\circ} \mathrm{c}$ and then thermo cycled for 500 cycles with dwelling time of 30 seconds and transfer time of 5 seconds, between $5^{\circ} \mathrm{C}$ and $55{ }^{\circ} \mathrm{C}$. For microleakage assessment, the radicular apices of teeth were sealed with sticky wax and root and crown surfaces of the teeth were completely covered with nail varnish except for 1-2 mm around the margins of restorations. Specimens were then engrossed in $2 \%$ methylene blue colorant $(\mathrm{PH}=7)$ for 24 hours, washed, dried and processed for dye extraction.

The teeth were placed in test-tube containing $3 \mathrm{ml}$ of concentrated $(65 \mathrm{wt} \%)$ nitric acid for 3 days and diluted with $3 \mathrm{ml}$ of distilled water. Test-tube are centrifuged (Universal 16R; Hettich ZentrifugenTuttlingen, Germany) at 5,000 rpm for 5 mins. 200 microliters of supernatant from each sample was transferred to a 96-well plate. Sample absorbance was read by an automatic spectrophotometer. The results of 
the spectrophotometer indicate the light incorporation of methylene blue in resin-dentin interface which is actually showing the microleakage of restoration. The results obtained were statistically analyzed and evaluated.

\section{Results}

In this study, mean microleakage score in teeth restored with group I,II \&III were $0.14498,0.13372$ \& 0.04622 respectively. Group III was statistically significant when compared to group I \& II $(P<0.05)$. The gingival/dentin margins showed significantly higher leakage than occlusal/enamel margins. when Groups I and II were compared, group II had better sealing ability than Group I and the results were statistically significant $(P<0.05)$. In bulkfill restorations with $4 \mathrm{~mm}$ increments Silorane-based composite showed more microleakage than Tetric N ceram. Nanohybrid (Group 2) showed less microleakage than Silorane (Group 1).. when group III was compared with group I \& II , results were highly significant ( P < 0.001). Fiber reinforced composite Ever X posterior is proven to be best bulkfill restoration compared to Silorane and Tetric $\mathrm{N}$ ceram.

Figures And Tables

Chart- 1

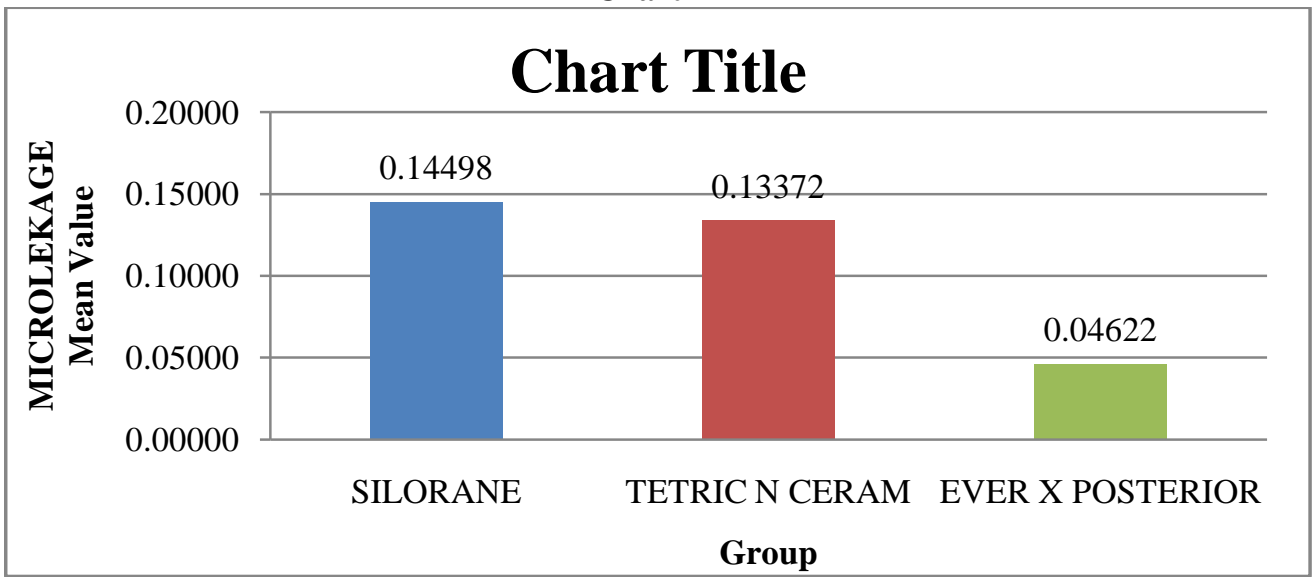

Microlekage Assessment

Table- 1: One Way Analysis Of Varience

\begin{tabular}{|c|c|c|c|c|c|c|c|c|c|}
\hline & \multirow[t]{2}{*}{$\mathrm{N}$} & \multirow[t]{2}{*}{ Mean } & \multirow[t]{2}{*}{$\begin{array}{c}\text { Std. } \\
\text { Deviation }\end{array}$} & \multirow[t]{2}{*}{ Std. Error } & \multicolumn{2}{|c|}{$\begin{array}{l}95 \% \text { Confidence Interval } \\
\text { For Mean }\end{array}$} & \multirow[t]{2}{*}{ Minimum } & \multirow[t]{2}{*}{ Maximum } & \multirow[t]{2}{*}{$\begin{array}{l}\text { ANOVA P } \\
\text { Value }\end{array}$} \\
\hline & & & & & $\begin{array}{l}\text { Lower } \\
\text { Bound }\end{array}$ & $\begin{array}{l}\text { Upper } \\
\text { Bound }\end{array}$ & & & \\
\hline Silorane & 15 & 0.14498 & 0.012 & 0.003 & 0.13806 & 0.15190 & 0.12000 & 0.16130 & $<0.001$ \\
\hline $\begin{array}{c}\text { Tetric } \mathrm{N} \\
\text { Ceram }\end{array}$ & 15 & 0.13372 & 0.012 & 0.003 & 0.12718 & 0.14026 & 0.11320 & 0.14810 & \\
\hline $\begin{array}{l}\text { Ever X } \\
\text { Posterior }\end{array}$ & 15 & 0.04622 & 0.007 & 0.002 & 0.04220 & 0.05024 & 0.03420 & 0.05680 & \\
\hline
\end{tabular}

\begin{tabular}{|c|c|c|c|c|c|c|}
\hline \multicolumn{7}{|c|}{ Table -2 Intergroup Comparision (Post Hoc Analysis) } \\
\hline \multirow[t]{2}{*}{ Group } & \multirow[t]{2}{*}{ (J) Group } & \multirow{2}{*}{$\begin{array}{c}\text { Mean } \\
\text { Difference } \\
(\mathrm{I}-\mathrm{J})\end{array}$} & \multirow[t]{2}{*}{ Std. Error } & \multirow[t]{2}{*}{ P Value } & \multicolumn{2}{|c|}{$\begin{array}{l}\text { 95\% Confidence } \\
\text { Interval }\end{array}$} \\
\hline & & & & & $\begin{array}{l}\text { Lower } \\
\text { Bound }\end{array}$ & $\begin{array}{l}\text { Upper } \\
\text { Bound }\end{array}$ \\
\hline Silorane & Tetric N Ceram & 0.01126 & 0.004 & 0.018 & 0.00170 & 0.02082 \\
\hline Silorane & Ever X Posterior & 0.09876 & 0.004 & $<0.001$ & 0.08920 & 0.10832 \\
\hline $\begin{array}{c}\text { Tetric N } \\
\text { Ceram }\end{array}$ & Ever X Posterior & 0.08750 & 0.004 & $<0.001$ & 0.07794 & 0.09706 \\
\hline
\end{tabular}




\section{Discussion}

Marginal integrity is essential to increase the longevity of any restoration. This integrity is compromised when microleakage occurs resulting from polymerisation shrinkage. MARGINAL LEAKAGE has been defined as, "The clinically undetectable passage of bacteria, fluids, molecules or ions between cavity walls \& the restorative material applied to it (Kidd 1976).". Microleakage may cause hypersensitivity, recurring caries, pulpal pathosis $\&$ its sequelae ${ }^{(.2,8,13,16)}$

To overcome the above mentioned problem, a newer low-shrinkage Silorane based composite was introduced. Silorane consists of traditional filler particles, whereas the conventional resin is replaced by silorane monomers. These resins are obtained from reaction of oxirane and siloxane molecules which attach other molecule during "ring opening" resulting in minimal polymerization shrinkage of less than $1 \%$. Hence, compared to methacrylate-based restorative materials, new silorane based material had the lowest polymerization shrinkage. It had relatively higher flexural strength, fracture toughness, but relatively lower compressive strength and micro hardness than the methacrylate-based restorative materials. So they had been included in our study as one of the experimental group.

In order to improve cavity wall adaptation and reduce microleakage, bulk fill composites were introduced for class II composite restorations due to their low modulus of elasticity, increased wettability, bulk filled composites may be useful in absorbing stresses and reducing microleakage caused by polymerization shrinkage .It has been shown that bulk composites have less microleakage and internal restoration voids and improved cavity adaptation and marginal sealing.Tetric $\mathrm{N}$ ceram bulk fill involving advanced composite filler technology, a pre-polymer shrinkage stress reliever, a light initiator/polymerisation booster and a light sensitivity filter .

The use of fibre-reinforced composites has become more and more essential over the recent years. Luthria et al ${ }^{12}$ has shown that reinforcement of fibres impart strength and toughness to composite resins. Glass fibres are known to be resistant to tension and are able to stop the propagation of fractures in the composite mass due to their high tensile strength, density and percentage of elongation allowing them to withstand high stresses without fracturing.

A new fibre reinforced composite ever $\mathrm{X}$ posterior reinforces the restorations with the strength of fibres. Total inorganic and filler content is $76 \mathrm{wt} \% / 57 \mathrm{vol} \%$. Manufacturers have claimed that the material can be used as dentine replacement, in conjunction with conventional composite in large restorations. The short fibres prevent and arrest crack propagation that often starts from the surface of the restoration. These fibres mimic the collagen fibres of dentine and therefore achieve a higher fracture toughness for restoration (5.1 $\mathrm{mpa} / \mathrm{m}^{1 / 2}$ ). This value exceeds that of dentine, which is a natural, fibre-reinforced material. Compared with other composites, the value is almost twice as high. The optimised length of glass fibres with everX Posterior results in high stability and hardness as well as effective adaptation of the material to the cavity wall... At this point, resistance to the formation of cracks or fissures is assumed as three times that of dentine and 10 times that of bone. EverX Posterior's properties make it suitable as a substructure to reinforce larger cavities in posterior area. Manufacturer recommends using everX Posterior for,

1. Cavities with three or more surfaces to be restored,

2. Cavities with missing dental cusps,

3. Deep cavities - class I and II cavities

4. Endodontically treated teeth

5. Cavities following amalgam removal.

Many studies have suggested the use of an incremental layering technique to reduce this shrinkage. Nowadays, traditional placement techniques for composite resins include this technique whereas most practitioners advocate of composites in $2 \mathrm{~mm}$ increments. However, every dentist who places posterior composite resins will prefer using a bulk fill technique hence, in the present study all three restorative materials have been evaluated for amount of microleakage when used in single increment as a bulk fill restorative material.

In the present study, forty five non carious human first molars were disinfected by using Chloramine T. As an N-Chloro compound, it contains active (electrophilic) chlorine and it can be compared to the $\mathrm{O}$ - chlorinated sodium hypochlorite. It is slightly basic $(\mathrm{Ph}=8.5)$. In water it breaks down to the disinfectant hypochlorite. Microleakage tested in the region of composite restoration was similar to freshly extracted teeth. ${ }^{24}$

In the current study, forty five non carious human first molars were taken to assess microleakage in class II restorations as these lesions are most commonly encountered in molars. In the present study gingival margin is placed below CEJ, because when prepared near CEJ it is made up of dentin and cementum. Bonding to dentin has always been poor compared to enamel. So, in the present in vitro study, all the class II cavities had similar dimensions with no bevel, same C- factor and the light curing mode was the same for all the restoration specimens so as to standardize the preparations. 
In the oral cavity, restorations are subjected to both thermal and mechanical stress that also contributes to the increase of marginal leakage. Thermo cycling is widely used method to determine if temperature variation might influence the bond strength and to simulate in vitro thermal changes that occur in the oral cavity. Hence in the present study, temperature was standardized at 5- 55 degree Celsius and dwell time was of 15 secs which seem to be tolerated by oral tissues.

To assess sealing efficiency of restorative material \& microleakage, the most common method is use of various dyes. Here, $2 \%$ methylene blue dye for 24 hours was chosen as the agent of dye extraction to measure microleakage because it is simple, economical, and does not require any complex laboratory apparatus. Even particle size of this dye is less than internal diameter of dentinal tubules $(1-4 \mu \mathrm{m})$, so it is able to show dentin permeability. ${ }^{8} 2 \%$ methylene blue dye for 24 hours was used by Ernst ${ }^{12}$ who concluded that this immersion period has a good correlation with marginal gaps evaluated by Scanning Electron Microscope.

However dye extraction methods are reported to give quantitative results. In this method, teeth are dissolved in acids that release all dye from the interface and optical density of solution is measured by adsorbing light via spectrophotometer. Thus it determines the penetrated dye volumetrically. It is fast method and can be carried out with minimal equipment available at most of the universities. Acc. to Pashley et al, there was no significant difference between fluid filtration and dye extraction method as both are based on quantitative measurements of liquids passing through porosity of the interface between the filling material and the tooth surface. Moreover, dye extraction method presents a benefit over fluid filtration technique, as filtration values tend to diminish over time, as the water penetrates all irregularities until a plateau is reached. ${ }^{12}$

In the present study, when Groups I and II were compared, group II had better sealing ability than Group I and the results were statistically significant $(P<0.05)$. In bulkfill restorations with $5 \mathrm{~mm}$ increments Silorane-based composite showed more microleakage than Tetric N ceram. Nanohybrid (Group 2) showed less microleakage than Silorane (Group 1). when group III was compared with group I \& II , results were highly significant $(\mathrm{P}<0.001$ ).Fiber reinforced composite Ever $\mathrm{X}$ posterior is proven to be best bulk fill restoration compared to Silorane and Tetric N ceram.

Hence, in the present study null hypothesis was rejected as there was significant difference in microleakage among three groups.

\section{Conclusion}

Based on the limitations of the present study, we can conclude that, "None of the restorative systems tested totally prevented microleakage in class II restorations regardless fiber reinforced ever $\mathrm{X}$ posterior showed least microleakage comparatively."

1. Silorane showed maximum microleakage when used as bulkfill restoration compared to Tetric $\mathrm{N}$ ceram and Ever X posterior.

2. Ever X Posterior showed least microleakage when used as bulkfill restoration.

\section{References}

[1]. M. Sadeghi .The Effect of Fluid Composite as Gingival Layer on Microleakage of Class II Composite Restorations.DRJ; 2007:4; 40-47.

[2]. Peris AR, Duarte S, de Andrade MF. Evaluation of marginal microleakage in class II cavities: Effect of microhybrid flowable,and compactable resins. Quintessence Int 2003;

[3]. 34:93-7.

[4]. Alani AH, Toh CG. Detection of microleakage around dental restorations: A review. OperDent 1997; 22:173-85.

[5]. Neiva IF, de Andrada MAC, Baratieri LN, Monteiro Júnior S, Ritter AV. An invitro study of the effect of restorative technique on marginal leakage in posterior composites. Oper Dent1998; 23:282-9.

[6]. Turkun LS, Aktener BO, Ates M. Clinical evaluation of different posterior resin composite materials: A 7-year report. Quintessence Int 2003;34:418-26.

[7]. Herrero AA, Yaman P, Dennison JB. Polymerization shrinkage and depth of cure of packable composites. Quintessence Int 2005;36:25-31.

[8]. Hilton TJ, Schwartz RS, Ferracane JL. Microleakage of four class II resin composite insertion techniques at intraoral temperature. Quintessence Int 1997;28:135-44.

[9]. Federlin $\mathbf{M}^{1}$, Thonemann B, Hiller KA, Fertig C, Schmalz G Microleakage in class II composite resin restorations: application of a clearing protocol. Clin Oral Investig. 2002 Jun;6(2):84-91.

[10]. Carmargo D.Evaluattion of the microleakage of standardized Class II restorations restored with two different resin composites; IJDR 2003; 12;23-28

[11]. Deliperi - DN Bardwell - C Wegley Restoration Interface Microleakage Using One Totaletch and Three Self-etch AdhesivesJOD2007:32; 179-184

[12]. Bagis YH, Baltacioglu IH, Kahyaogul ari S. Comparing microleakage and the layering methods of silorane - based resin composite in wide class II MOD cavities. Oper Dent 2009;34:578-85.

[13]. Mithra N Hegde, Pallavi Vyapaka, Shishir ShettyA .comparative evaluation of microleakage of three different newer direct composite resins using a self etching primer inclass V cavities: An in vitro study JCD2009;12:160-3

[14]. M. Moezyzadeh , M. Kazemipoor .Effect of Different Placement Techniques on Microleakage of Class V Composite RestorationsJOD,Tehran,Iran;2009:6;121-9 
[15]. Radhika M, Girija S Sajjan, Kumaraswamy B N, Neetu Mittal.Effect of different placement techniques on marginal microleakage of deep class-II cavities restored with two composite resin formulations. JCD: 2010; 13:9-15

[16]. Al boni R. and Raja OM. Microleakage evaluation of Silorane based composite versus methacrylate based composite.J Conser Dent 2010;13(3):152-55

[17]. Lien W. Physical properties of a new silorane-based restorative system; dental materials 26; (2010); 337-344

[18]. Umer F et al, An in vitro evaluation of microleakage in class V restorations with hybrid versus Silorane composites;2011;14;2;1037

[19]. Claudio Poggio 1, Marco Chiesa 1, Andrea Scribante 2, Jenia Mekler 1, Marco ColomboMicroleakage in Class II composite restorations with margins below the CEJ: Invitro evaluation of different restorative techniques. Med Oral Patol Oral Cir Bucal. 2013 Sep1;18 (5):e793-8

[20]. Joseph A. Microleakage evaluation of Silorane based composite and methacrylate based composite in class II box preparations using two different layering techniques - an in vitro study. Indian J Dent Res 2013;24:148

[21]. Bala O, Octasli MB, Onlu I. The leakage of class II cavities restored with packable resin based composites. J Contemp Dent Pract 2003;4:1-7. 